\title{
Effect of carcass contamination on necrophagous invertebrate performance
}

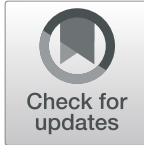

Ellard R. Hunting ${ }^{1,2^{*}}$ D, Maarten Schrama ${ }^{1,3}$, Daniel E. Rozen ${ }^{4}$, Christina Joenssen ${ }^{1}$ and Nadja R. Brun ${ }^{1,5^{*}}$

\begin{abstract}
Background: The breakdown of dead organic matter is driven by a diverse array of organisms and is an important process increasingly impacted by a range of contaminants. While many studies have documented how contaminants affect food webs that are fueled by decaying plant litters, much less is known about how contaminants affect organisms that rely on dead animal material. Here, we begin to explore the effects of food contamination —using silver nanoparticles (AgNPs) as a model contaminant-on the carrion beetle Nicrophorus vespilloides that buries carcasses of small vertebrates in soils as food source and larval nursing grounds.

Results: Our data show that a single ingestion of a non-lethal dose of $1 \mu \mathrm{g} \mathrm{mL}^{-1}$ AgNPs by adult female beetles does not affect overall gut microbial activity but results in shifts in the gut microbial community composition towards pathogens including Alcaligenes, Morganella, and Pseudomonas. While no effects were observed in offspring clutch size, some reductions were visible in clutch weight, number of larvae, and number of eclosing pupae in exposed $N$. vespilloides in comparison with controls. Repeated ingestion of AgNPs over several weeks led to a decrease in survival of adult beetles, suggesting that more environmentally realistic exposure scenarios can directly affect the success of carcass-feeding animals.

Conclusions: Sub-lethal carcass contamination with a model pollutant can affect the gut microbial composition in female beetles and reduce offspring fitness. This encourages consideration of currently overlooked propagation routes of contaminants through necrophagous food webs and inherent consequences for ecological and evolutionary processes.
\end{abstract}

Keywords: Gut microbiome, Maternal transfer, Offspring fitness, DECOTAB, Nanoparticles, Bactericidal compounds, Carrion beetle, Nicrophorus vespilloides

\section{Introduction}

Dead organic matter fuels food webs by serving as a food source for a diverse array of organisms, ranging from microorganisms and macroinvertebrates to scavenging megafauna. While most of the dead organic matter originates from senescent plant materials, carcasses of organisms provide a particularly high-quality and seemingly preferred resource to a variety of organisms and create an intense, localized pulse of carbon and nutrients into the environment (e.g., Wilson and Wolkovich 2011;

\footnotetext{
*Correspondence: e.r.hunting@bristol.ac.uk; nadja.brun@uib.no

'Institute of Environmental Sciences, Leiden University, Leiden, The Netherlands

Full list of author information is available at the end of the article
}

Schrama et al. 2017). The continuous release of chemicals into the environment by humans, however, can directly affect an organism's health or indirectly affect organisms by reducing the quality of their resources as contaminants accumulate in organic matter (Theng and Yuan 2008). This potentially provides a substantial propagation route of contaminants through food webs. Indeed, many studies have documented how contaminants can accumulate in plant matter-fueled food webs and affect consumers that feed on living as well as dead plant material (e.g., Judy et al. 2011; Hunting et al. 2016). Yet, little is known about how contaminants affect food webs that rely on dead animal material. 
Some studies have addressed this issue and showed that anti-inflammatory drugs and antibiotics present in cattle carcasses can accumulate in organisms (e.g., vultures) that feed directly on dead organic matter (Oaks et al. 2004; Blanco et al. 2019, 2016). In addition to direct consumption, some animals are reliant on carcasses to rear their offspring, and it is conceivable that contaminants can adversely affect such life history strategies and characteristics. A relatively well-studied example of such a necrophagous organism is the carrion beetle Nicrophorus vespilloides that lives in forests where it seeks and buries small vertebrate carcasses (e.g., rodents or birds). These carcasses are scarce but essential for reproductive success. The carcasses are intricately prepared as a rearing ground for their larvae through the manipulation of the carcasses' microbial community. This occurs through the excretion of antimicrobial compounds and the inoculation of the beetles' well-defined gut microbiome that is transmitted both vertically from the parents and horizontally from the carcass (Kaltenpoth and Steiger 2014; Wang and Rozen 2017). Here, the microbiota of carrion beetles is particularly relevant for their offspring as it enhances defense against pathogens and preserves carrion, thereby aiding in the development of larvae (e.g., Kaltenpoth and Steiger 2014; Wang and Rozen 2017; Shukla et al. 2018). Provided that gut microorganisms are generally recognized to fulfill many pivotal roles in host functions essential for fitness (Bright and Bulgheresi 2010; Heijtz et al. 2011; Hsiao et al. 2013; Kau et al. 2011; Engel and Moran 2013; Funkhouser and Bordenstein 2013), alterations in the gut microbiota can conceivably have adverse effects on their host and offspring.

Contaminants of particular interest are pollutants with antimicrobial properties, including antibiotics, heavy metals, persistent organic pollutants, and pesticides (Jin et al. 2017). Although most of these environmental pollutants do not directly target the gut microbiome, their major route of uptake is through ingestion associated with food items that indirectly target the gut microbiota. Previous studies indeed confirm that contaminants can accumulate in the guts of animals, thereby potentially affecting the gut microbiota of the host (Ding et al. 2019) which could translate to adverse effects on invertebrate fitness. The dysbiosis of the maternal microbiome potentially translates to fewer resources being invested in producing offspring or adverse effects on offspring in growth and survival (Arce et al. 2012; Kaltenpoth and Steiger 2014; Wang and Rozen 2017). However, studies hitherto report contradictive effects with respect to the significance of microbiomes for their host's health (e.g., mice, zebrafish, and daphnids), ranging from no compositional changes of the microbiome to severe adverse effects on reproduction and growth (Merrifield et al. 2013; Sison-Mangus et al. 2014; van den Brule et al. 2015; Wilding et al. 2016).
This study centers on the hypothesis that the accumulation of contaminants in organisms can have postmortem effects on the organisms that use these carcasses as food and nursery grounds. To begin to test this assumption, we used the carrion beetle $N$. vespilloides in wellcontrolled laboratory incubations and assessed the effects of one feeding episode on a mimicked carcass with sub-lethal contaminant concentrations on (1) maternal microbiome composition and metabolic activity and (2) fitness parameters of their offspring. Subsequently, the effect of chronic consumption of a contaminated food source on the survival of adults was assessed.

\section{Materials and methods}

\section{Experimental setup}

The carrion beetles Nicrophorus vespilloides (Herbst, 1783) used in this study were caught from a wild population in 2014 (May to June) from Warmond (The Netherlands) and ever since maintained in the laboratory in unsterilized commercially available garden soil (baseline). Mating between sibling pairs was avoided to maintain an outbred population (Mattey et al. 2013). Beetles were reared in climate chambers at $20^{\circ} \mathrm{C}$ under a constant light-dark cycle ( $15 \mathrm{~h}$ light- $9 \mathrm{~h}$ dark) and were fed chicken liver at weekly intervals.

Exposure diet was prepared using DEcomposition and COnsumption TABlets, or DECOTABs in short, that can embed a homogenized and standardized mixture of contaminants in a standardized substrate (Kampfraath et al. 2012; Van der Lee et al. 2020). DECOTABs were prepared as $1-\mathrm{mL}$ frozen tablets using an acrylic mold with a mixture of chicken liver and cornstarch (Kampfraath et al. 2012). Silver nanoparticles (AgNPs) were used as a model toxic compound as they represent an emerging class of toxicants (Fabrega et al. 2011; Gottschalk et al. 2013; Pillai et al. 2014). AgNPs have known antimicrobial properties in which they affect the permeability and respiration of the bacterial cell, ultimately leading to cell death (Dakal et al. 2016) and shifts in bacterial community composition (Zhai et al. 2016; Tlili et al. 2017; Zhai et al. 2018). AgNPs with a nominal particle size of $15 \mathrm{~nm}$ were purchased from Nanostructured \& Amorphous Materials (Houston, USA). Characterization of the particle morphology of the AgNP is described elsewhere (Zhai et al. 2018). It is technically challenging to disentangle the relative contributions of nanoparticles and ions within complex systems such as the food item served here (chicken liver); hence, the agglomeration dynamics and ratio of AgNPs and ions were not assessed in the DECOTABs. To confirm that AgNPs were actually ingested, the guts (control $n=16$; AgNP $1 \mu \mathrm{g} \mathrm{mL}^{-1}, n=17$ ) were extracted and homogenized using a conical plastic pestle in 2.0-mL Eppendorf with $1.5 \mathrm{~mL}$ sterile phosphate buffer saline (PBS; $100 \mathrm{nM}$; pH 
7.2). The samples of the gut mixture were acidified with a mixture of $5 \% \mathrm{HNO}_{3}$ and PBS adding up to $3 \mathrm{~mL}$. The concentration of silver was then assessed by graphite furnace atomic absorption spectrometry (GF-AAS), and standards of silver nitrate $\left(0.1,1,10,100 \mu \mathrm{g} \mathrm{L}^{-1}\right)$ were used to establish a calibration curve.

\section{Experimental design}

Intergenerational effects of consumption of AgNPs on offspring fitness were evaluated by serving DECOTABs with $1 \mu \mathrm{g} \mathrm{mL}^{-1}$ AgNPs to adult female beetles and compared these with a control group ( $n=20$ per group) that were served DECOTABs without AgNPs. In a preliminary study, three AgNP exposure concentrations $(0.1,1$, and $\left.5 \mu \mathrm{g} \mathrm{mL}^{-1}\right)$ were tested for lethality within 7 days $(n$ $=20$, data not shown). While none of the exposures resulted in mortality, the highest concentration reduced the beetle activity, and therefore, all subsequent experiments were performed using $1 \mu \mathrm{g} \mathrm{mL} \mathrm{m}^{-1}$. Under natural conditions, carrion beetles give bi-parental care to their brood at the pre-hatching stage (Steiger et al. 2011). However, to reduce variability, the setup includes maternal care only throughout all stages. Before exposure to AgNPs, we ensured that the weight of the female beetles did not differ between the control and exposure groups (control vs exposure, $0.194 \pm 0.037$ (STD) vs $0.197 \pm 0.044(\mathrm{STD}) \mu \mathrm{g}$; Student $t$-test: $n=20, p=$ $0.810)$. After female beetles were assigned to a treatment, the unmated female beetles were put in Petri dishes containing a layer of filter paper soaked with 1-
$\mathrm{mL}$ water to keep the air moist and were then left at $20^{\circ} \mathrm{C}$ for 2 days to consume the DECOTABs (see Fig. 1 for a conceptual presentation of the experimental outline). After consuming the DECOTABs, the female was placed in a Petri dish with an adult male to mate for 24 $\mathrm{h}$, after which the female was placed in a plastic container of $15 \times 10 \times 5 \mathrm{~cm}$ containing $30-\mathrm{cm}^{3}$ unsterilized potting soil and a mouse carcass weighing between 16 and $31 \mathrm{~g}$. Mouse carcasses were kindly provided by the laboratories of Leiden University Hospital.

\section{Effect of carcass contamination on parental microbiome composition and metabolic activity}

The overall respiratory capacity of the gut microbiome of the control and AgNP-exposed beetles was approximated by dehydrogenase enzyme activity via the reduction of 2-(p-iodophenyl)-3-(p-nitrophenyl)-5-phenyl tetrazolium chloride (INT) to formazan (INTF). INT successfully competes with $\mathrm{NADH}^{+}$and $\mathrm{NADPH}^{+}$and therefore INT reduction is a common assay of respiratory activities under both anaerobic and aerobic conditions (Smith and McFeters 1996). The guts $(n=10$ per group) were extracted and homogenized in a $100-\mu \mathrm{L}$ PBS solution using an autoclaved plastic pestle. This gut mixture was filtered through a cell strainer $(40 \mu \mathrm{m}$ Nylon) to obtain a clear solution containing microbial cells without gut tissue. To measure enzymatic activity, a $5-\mu \mathrm{L}$ aqueous INT solution $(200 \mu \mathrm{L} ; 1 \mathrm{mM}$ with $0.05 \%$ dimethyl sulfoxide (DMSO)) was added to each gut extract, consisting of $5 \mu \mathrm{L}$ of strained gut solution from

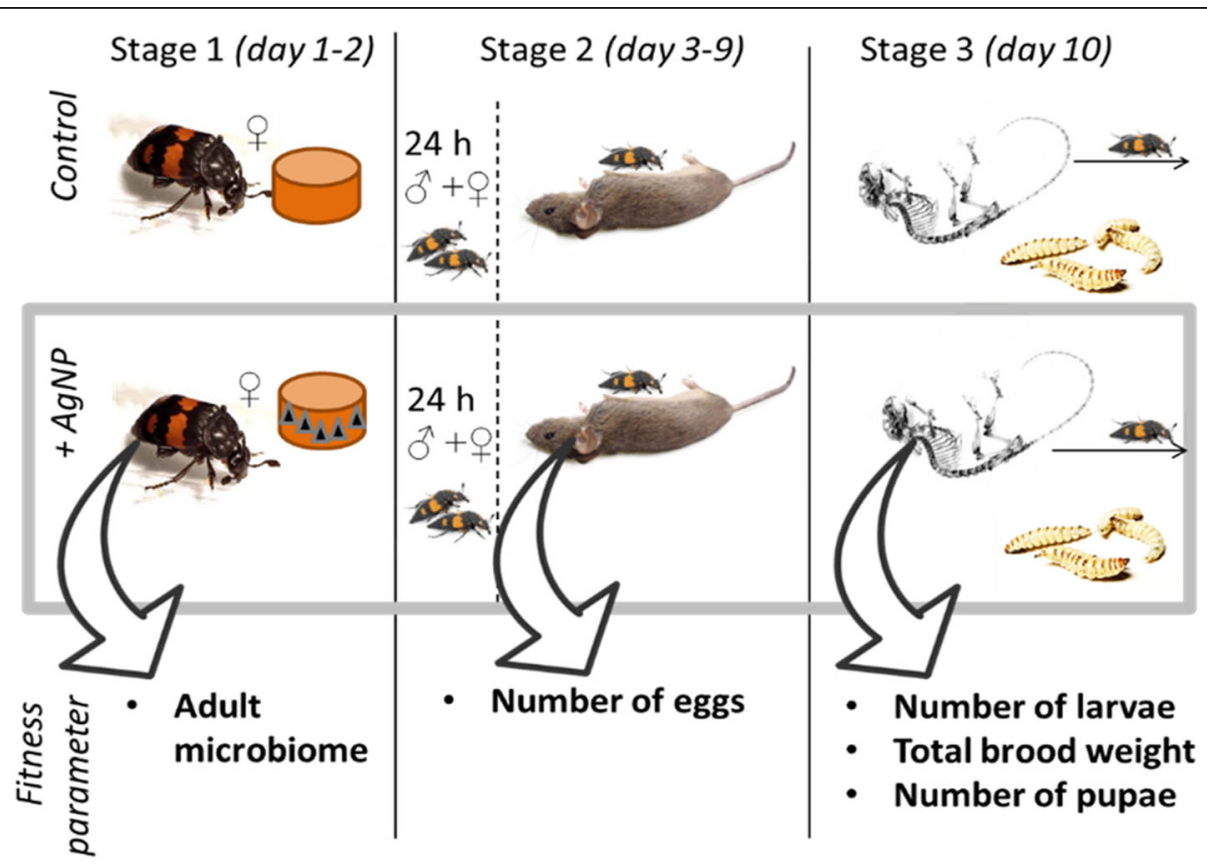

Fig. 1 Conceptual diagram of the experimental outline. The bottom row indicates the fitness parameters that were collected at each of the stages of the experiment for beetles of control treatments without AgNPs and beetles that ingested $1 \mu \mathrm{g} \mathrm{mL}^{-1} \mathrm{AgNP}_{\text {-contaminated food items }}$ 
individual beetles. Samples were incubated in a dark room at $22^{\circ} \mathrm{C}$ for $3 \mathrm{~h}$, and thereafter, enzyme activity was stopped and INT formazan crystals were solubilized by adding $5 \mu \mathrm{L}$ DMSO. Absorbance reflecting the dehydrogenase activity was measured using a NanoDrop $2000 / 2000$ c at $585 \mathrm{~nm}$ and corrected for microbial cell density measured at $600 \mathrm{~nm}$ (gut solution without INT), in which both were baseline-corrected using the aforementioned incubation solution without microbial cells (Hunting et al. 2010). Microbial density was found to be variable among the guts of individual beetles, and therefore, the microbial activity of the exposed beetles and the control group was expressed as dehydrogenase activity measured at an absorbance at $585 \mathrm{~nm}$ relative to microbial cell density measured at $600 \mathrm{~nm}$ to obtain a measure of metabolic activity per unit cell density, in which relative activity equals $0.1 \times\left(A_{585} / A_{600}\right)$.

To obtain a qualitative structural account of the effect of AgNPs on the microbial gut composition, we used CHROMagar Orientation. CHROMagar allows differentiation and presumptive identification of bacteria. CHROMagar Orientation was purchased from the manufacturer CHROMagar (Paris, France) in powder base (agar, $15 \mathrm{~g} \mathrm{~L}^{-1}$; peptone and yeast extract, $17 \mathrm{~g} \mathrm{~L}^{-1}$; chromogenix mix, $1 \mathrm{gL}^{-1}$ ). The plates were made with $33 \mathrm{~g}$ of CHROMagar Orientation powder base dissolved in $1 \mathrm{~L}$ of purified water. The guts of the exposed beetles $(n=4)$ and the control $(n=5)$ were extracted and homogenized within a $750-\mu \mathrm{L}$ PBS solution and then diluted with autoclaved ultrapure water to obtain a final volume of $5 \mathrm{~mL}$. Each gut was then plated on $3 \mathrm{CHRO}-$ Magar plates and incubated for $24 \mathrm{~h}$ at $32^{\circ} \mathrm{C}$, after which the colony-forming units (CFU) were determined and counted, and the mean of the three plates per gut was calculated.

To assess whether the gut microbial communities were different depending on treatment, we assessed substrate utilization profiles using commercial EcoPlates (Biolog, Hayward, USA). Each well plate contains 3 replicates comprising 31 different carbon substrates which are ecologically relevant and structurally diverse compounds. Since it does not include specific compounds typical of the food items used in this study, it remains impossible to directly relate substrate utilization profiles to the actual functioning of the microbiome. Nonetheless, the number of substrates used can serve as a proxy for the (metabolic) diversity and resource niche breadth of the microbial community (Garland 1999; Hunting et al. 2013; Krause et al. 2014; Hunting et al. 2017). For this experiment, the gut microbial community of beetles that ingested chicken liver laced with AgNP $\left(1 \mu \mathrm{g} \mathrm{mL}^{-1}, n=\right.$ 4) was compared to the microbial community of control beetles $(n=5)$ that ingested chicken liver only. The guts were extracted and homogenized in $700 \mu \mathrm{L}$ PBS and
$4300 \mu \mathrm{L}$ purified water, which then was dispersed between 3 replicates with $50 \mu \mathrm{L}$ in each well. The EcoPlates were then incubated at $20^{\circ} \mathrm{C}$ for 5 days in dark conditions and thereafter measured at $600 \mathrm{OD}$ using a standard plate reader.

\section{Offspring fitness}

After exposure and mating, the female was left to take care of her young until the offspring started to disperse from the mouse carcass to go into the pupal stage (Mattey et al. 2013). The time of dispersal varied ranging from 9 to 10 days post-hatching, which was similar between treatments. We collected the following four fitness measures after mating control and exposed female beetles ( $n=20$ per treatment group) with unexposed males: (1) the number of eggs produced by the female beetles after the burial of the mouse, as counted at the bottom of the plastic container; (2) the number of larvae present after the larvae dispersed (by sorting through the soil); (3) the total brood weight of the larva at dispersal; and (4) the number of eclosing pupae (Fig. 1).

\section{Survival of adult beetles after chronic exposure}

A repeated exposure experiment was set up to assess chronic, and thereby more environmentally realistic, effects on survival. Female beetles were fed DECOTABs with or without $1 \mu \mathrm{g} \mathrm{mL}^{-1}$ AgNPs as described above, and the treatment was repeated every 7 days. The weight of the beetles in the first experiment was $0.230 \pm 0.043$ $\mu \mathrm{g}$ (STD) for the control and $0.210 \pm 0.051 \mu \mathrm{g}$ (STD) for the exposed group (Student $t$-test $p=0.365$ ), and in the second experiment, the weight was $0.280 \pm 0.037 \mu \mathrm{g}$ (STD) for the control and $0.270 \pm 0.049 \mu \mathrm{g}$ (STD) for the exposed group (Student $t$-test $p=0.786$ ). The first experiment lasted for 36 days ( $n=10$ per group), and the second experiment had to be terminated due to unforeseen events at the laboratory after 27 days $(n=10$ per group). The beetles were checked daily for survival.

\section{Statistical analysis}

To assess meaningful differences between the control and treatment groups taking into account the effect size, Ag concentrations in the gut, enzyme activity, and beetle offspring parameters were analyzed using estimation statistics and depicted as Gardner-Altman plots (Ho et al. 2019). For comparison, a two-tailed permutation $t$-test was performed. Both tests build upon resampling the measured data, and therefore, the data will approach a normal distribution even if the underlying population is not normally distributed. Differences in bacterial community substrate utilization profiles in exposed and control treatments were visualized using a principal component analysis (PCA) and tested performing a Euclidean-based ANOSIM in PAST (Villéger et al. 
2008; Hammer et al. 2001). The differentiation of microbial species determined using CHROMagar was depicted in pie charts for visual comparison, and each species was tested for proportional differences between treatment and control using a $Z$-test. The survival of the female beetles in the chronic exposure was drawn using the Kaplan-Meier estimates of the survival functions and analyzed with a Mantel-Cox log-rank test. All statistics are summarized in Table 1.

\section{Results}

Effect of carcass contamination on parental gut microbial composition and activity

Silver was measured to accumulate in the guts of the exposed beetles where all concentrations of exposed beetle guts were clearly above the detection limit $(0.026 \mathrm{ppb})$ and the concentrations of control beetle gut below the detection limit (Fig. 2). Microbial activity as shown using the results of the relative dehydrogenase activity was in a similar range in the exposed beetles compared to the control beetles (permutation $t$-test, $p=$ 0.084, Fig. 3A). The (metabolic) composition of the gut microbial community was different between exposed and control treatments (Fig. 3B, one-way ANOSIM, Euclidean-based similarity, $n=4, R=0.969, p=$ 0.030). The composition of the colony-forming units between both the treatments was different for a number of taxa, as shown using the results of the CHROMagar plates (Fig. 3C). Exposure to nanoparticles decreased the abundance of Candida and Serratia (Fig. 3C) while promoting the growth of Alcaligenes, Morganella, and Pseudomonas (Z-test, $p<0.05)$.

\section{Effects of carcass contamination on offspring fitness}

There was no difference in clutch sizes between the exposed and control treatments (permutation $t$-test, $p=$
0.239; Fig. 4A). The development into larvae within 10 days showed a tendency of being reduced in the exposed group (permutation $t$-test, $p=0.050$; Fig. $4 \mathrm{~B}$ ) as did the total larval brood weight in the exposed group in comparison with the control (permutation $t$-test, $p=0.037$; Fig. 4C). In connection with those results, the number of larvae reaching the pupal stage was similarly reduced (permutation $t$-test, $p=0.111$; Fig. 4D). The larval weight did not appear to vary with carcass weight $(y=$ $\left.0.0008713 x+0.15753, R^{2}=0.0063, p=0.618\right)$.

\section{Effects of carcass contamination on adult survival}

Continuous exposure to AgNP over the course of 4 weeks impaired the survival of the beetles (Fig. 5; pool of two experiments, Mantel-Cox log-rank test, $p=0.016$ ).

\section{Discussion}

This study explored the direct and indirect effects of carrion contamination with a bacteriocidal compound (AgNP) on the gut microbiome and offspring fitness of the carrion beetle $N$. vespilloides. Our findings indicate that, at levels that do not result in acute toxicity, a single feeding event on an AgNP-contaminated food source can influence the composition of the beetle microbiome without clearly affecting its overall metabolic activity. The resulting alteration of the gut microbiome potentially translates to the observed subsequent effects on their offspring which rely on the maternal transmission of the microbiome and may be related to the observed increased mortality of adult beetles in chronic exposure.

While a single exposure to silver nanoparticles did not appear to alter the overall gut microbial activity, a compositional change was observed in gut microbial communities in $N$. vespilloides. The abundance of certain strains such as Serratia sp., a group of gram-negative bacteria that includes opportunistic insect pathogens

Table 1 Summary of statistical test results

\begin{tabular}{|c|c|c|c|c|c|c|}
\hline Assay & $\begin{array}{l}n \\
\text { (control) }\end{array}$ & $\begin{array}{l}n \\
\text { (exposed) }\end{array}$ & $\begin{array}{l}\text { Effect size }[\mathrm{Cl} \text { width lower bound; } \\
\text { upper bound] }\end{array}$ & $\begin{array}{l}\text { Two-sided } \\
\text { permutation } t \text {-test }\end{array}$ & $\begin{array}{l}\text { Euclidean-based } \\
\text { ANOSIM }\end{array}$ & $\begin{array}{l}\text { Log-rank (Mantel- } \\
\text { Cox) test }\end{array}$ \\
\hline $\begin{array}{l}\text { Gut Ag } \\
\text { concentration }\end{array}$ & 16 & 17 & $1.36[95 \mathrm{Cl} 1.07 ; 1.65]$ & $p=0.000$ & & \\
\hline $\begin{array}{l}\text { Dehydrogenase } \\
\text { activity }\end{array}$ & 10 & 10 & $-0.00724[95 \mathrm{Cl}-0.0147 ;-0.000163]$ & $p=0.084$ & & \\
\hline Biolog EcoPlate & 5 & 4 & & & $p=0.030$ & \\
\hline \multicolumn{7}{|l|}{ Offspring fitness } \\
\hline $\begin{array}{l}\text { Eggs per } \\
\text { clutch }\end{array}$ & 20 & 20 & $-3.5[95 \mathrm{Cl}-8.9 ; 2.46]$ & $p=0.239$ & & \\
\hline $\begin{array}{l}\text { Larvae } \\
\text { emerging }\end{array}$ & 16 & 19 & $-6.82[95 \mathrm{Cl}-13.3 ;-0.694]$ & $p=0.050$ & & \\
\hline Clutch weight & 16 & 19 & $-0.973[95 \mathrm{Cl}-1.9 ;-0.169]$ & $p=0.037$ & & \\
\hline Pupal stage & 16 & 19 & $-6.82[95 \mathrm{Cl}-13.3 ;-0.694]$ & $p=0.111$ & & \\
\hline Chronic mortality & 20 & 20 & & & & $p=0.016$ \\
\hline
\end{tabular}




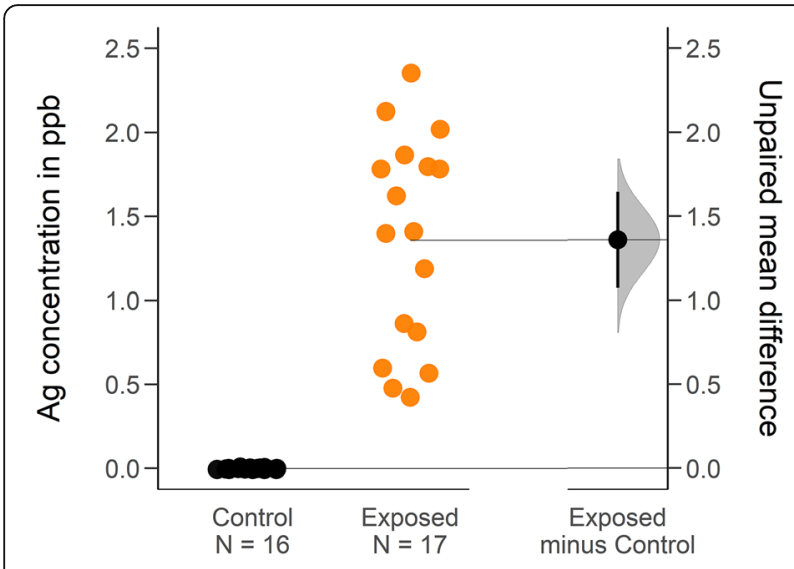

Fig. 2 Concentration of silver in control and AgNP-exposed carrion beetle guts. All values for controls were below the detection limit
(Flyg et al. 1980; Motta et al. 2018), was decreased while the growth of other strains exhibited a relative increase. Such differences are potentially due to the sensitivity of certain bacterial strains to AgNPs, particularly gramnegative bacteria (Choi et al. 2008; Ip et al. 2006). This result is in line with an increasing number of studies that demonstrate the consequences of environmental contaminant exposure can include shifts in symbiont and pathogen abundances (Motta et al. 2018). This can have potential implications for the metabolism as an altered bacterial composition may affect the success in extracting nutrients from the food provided and have subsequent knock-on effects on fitness (Cornman et al. 2016; Gupta et al. 2011; Kaltenpoth and Steiger 2014; Lehman et al. 2009). However, the actual underlying mechanisms often remain poorly understood, and this remains a key challenge for future research. Since the gut microbiome is likely more diverse in wild specimens

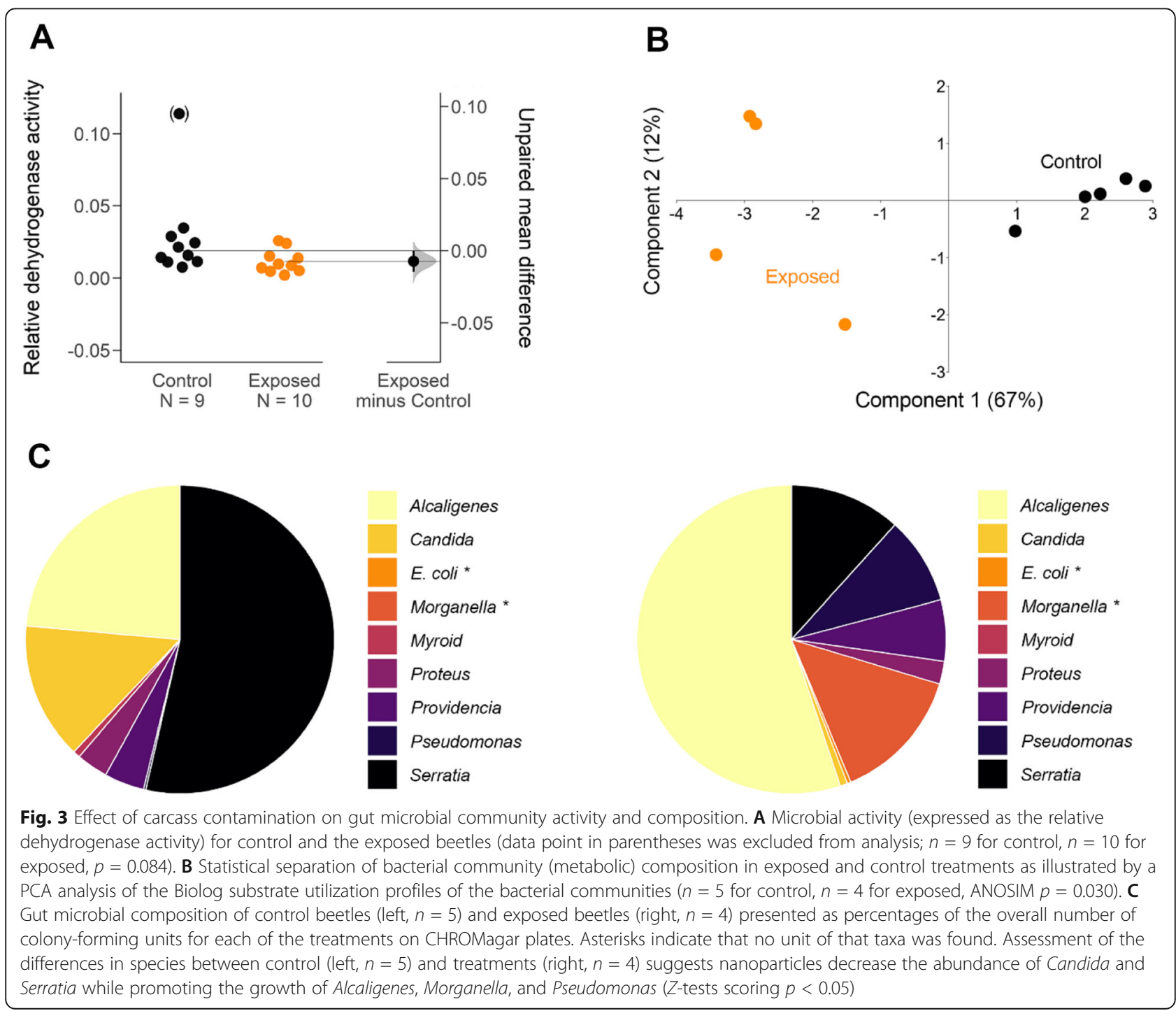



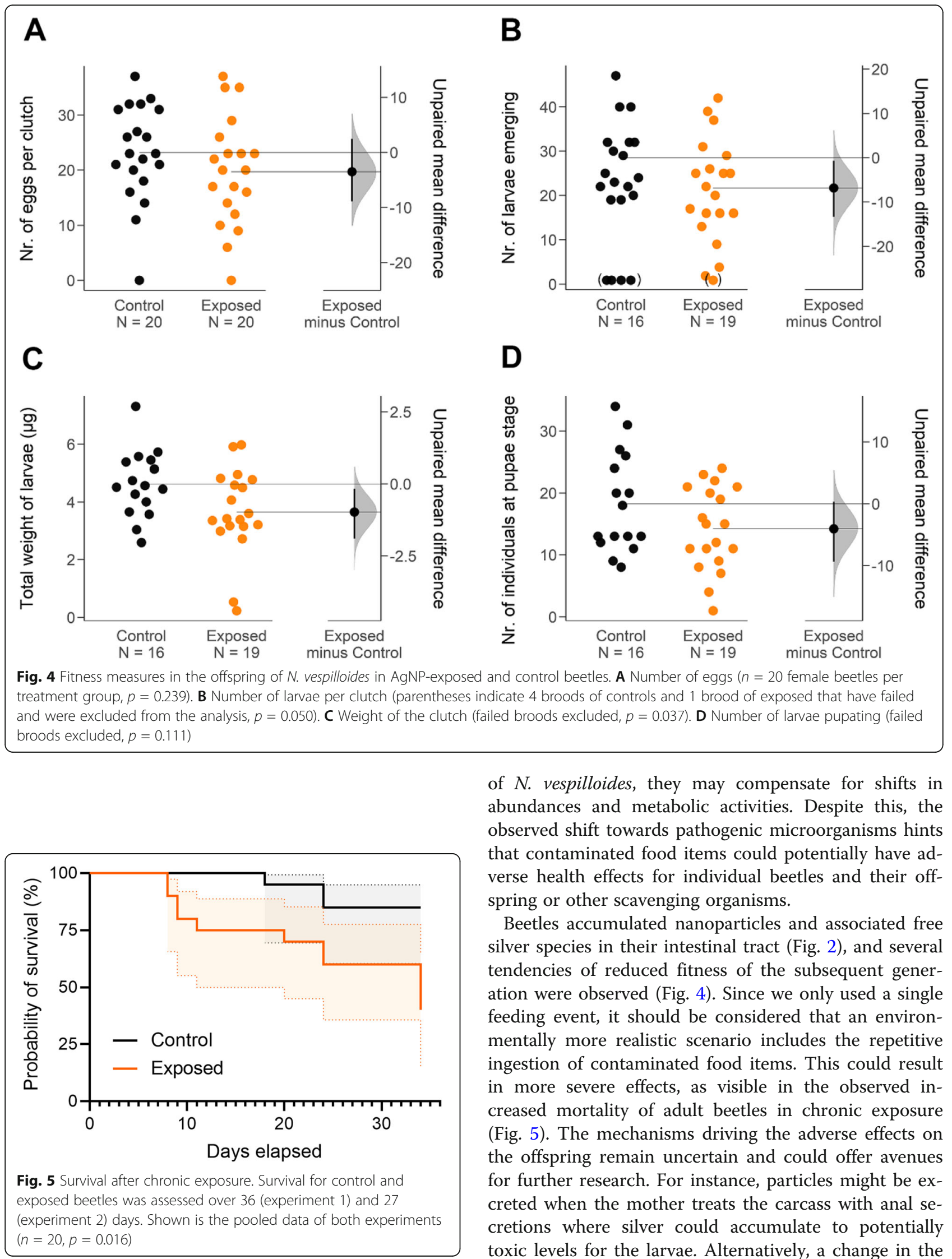

of $N$. vespilloides, they may compensate for shifts in abundances and metabolic activities. Despite this, the observed shift towards pathogenic microorganisms hints that contaminated food items could potentially have adverse health effects for individual beetles and their offspring or other scavenging organisms.

Beetles accumulated nanoparticles and associated free silver species in their intestinal tract (Fig. 2), and several tendencies of reduced fitness of the subsequent generation were observed (Fig. 4). Since we only used a single feeding event, it should be considered that an environmentally more realistic scenario includes the repetitive ingestion of contaminated food items. This could result in more severe effects, as visible in the observed increased mortality of adult beetles in chronic exposure (Fig. 5). The mechanisms driving the adverse effects on the offspring remain uncertain and could offer avenues for further research. For instance, particles might be excreted when the mother treats the carcass with anal secretions where silver could accumulate to potentially toxic levels for the larvae. Alternatively, a change in the 
microbiota may lead to behavioral changes in the female beetle which can potentially affect brood care. Likewise, silver nanoparticles could have affected the mother's health via mechanisms other than dysbiosis of the gut microbiome, or an inhibited or impaired microbiota might have prevented the maternal transfer of microorganisms critical to the healthy development of the offspring (Jacobs et al. 2014). It would be further interesting to directly expose the carcass that is used as rearing ground and assess its effect on offspring fitness independent of the exposed parents.

Using a simplified model setup mimicking a carcassdependent food web, we observed that food contamination with a model antibacterial compound (AgNP) can alter the metabolic diversity of the burying beetle Nicrophorus vespilloides microbiome. The observed patterns on gut microbiomes likely hold true for myriad contaminants as many have antibacterial and antifungal properties. The resulting alteration of the gut microbiome could potentially be the cause of increased mortality of adult beetles in chronic exposure. A single feeding event was observed to have some apparent, albeit minor effects on offspring, but it should be considered that a more realistic repetitive exposure to contaminants could potentially coincide with a stronger negative effect on the fitness of their offspring. The observed effects in our model necrophagous food web may be relevant for other scavengers that rely on the maternal transfer of microbiomes and encourage consideration of currently overlooked propagation routes of contaminants through food webs.

\section{Acknowledgements}

We gratefully acknowledge the expert assistance with beetle maintenance from Kees Koops and chemical supplies from Martina Vijver.

\section{Authors' contributions}

EH: conceptualization, experimental design, data analysis, writing, and editing. MS: data analysis, writing, and editing. DR: experimental design and editing. CJ: experiments. NB: conceptualization, experimental design, data analysis, writing, and editing. The authors read and approved the final manuscript.

\section{Funding}

No funding.

\section{Availability of data and materials}

The datasets used and/or analyzed during the current study are available from the corresponding authors on reasonable request.

\section{Declarations}

Ethics approval and consent to participate

Not applicable.

\section{Consent for publication}

Not applicable.

\section{Competing interests}

The authors declare that they have no competing interests.

\section{Author details}

${ }^{1}$ Institute of Environmental Sciences, Leiden University, Leiden, The Netherlands. ${ }^{2}$ School of Biological Sciences, University of Bristol, Bristol, UK. ${ }^{3}$ Naturalis Biodiversity Centre, Leiden, The Netherlands. ${ }^{4}$ Institute of Biology, Leiden University, Leiden, The Netherlands. ${ }^{5}$ Current Address: Department of Biological Sciences, University of Bergen, Bergen, Norway.

Received: 19 May 2021 Accepted: 13 July 2021

Published online: 09 August 2021

\section{References}

Arce AN, Johnston PR, Smiseth PT, Rozen DE (2012) Mechanisms and fitness effects of antibacterial defences in a carrion beetle. J Evol Biol 25(5):930-937. https://doi.org/10.1111/j.1420-9101.2012.02486.x

Blanco G, Cortés-Avizanda A, Frías Ó, Arrondo E, Donázar JA (2019) Livestock farming practices modulate vulture diet-disease interactions. Glob Ecol Conserv 17:e00518. https://doi.org/10.1016/J.GECCO.2018.E00518

Blanco G, Junza A, Segarra D, Barbosa J, Barrón D (2016) Wildlife contamination with fluoroquinolones from livestock: widespread occurrence of enrofloxacin and marbofloxacin in vultures. Chemosphere 144:1536-1543. https://doi. org/10.1016/J.CHEMOSPHERE.2015.10.045

Bright M, Bulgheresi S (2010) A complex journey: transmission of microbial symbionts. Nat Rev Microbiol 8(3):218-230. https://doi.org/10.1038/ nrmicro2262

Choi O, Deng KK, Kim N-J, Ross L, Surampalli RY, Hu Z (2008) The inhibitory effects of silver nanoparticles, silver ions, and silver chloride colloids on microbial growth. Water Res 42(12):3066-3074. https://doi.org/10.1016/J.WA TRES.2008.02.021

Cornman RS, Dainat J, De Miranda JR, Doublet V, Emery O, Evans JD, Farinelli L, Schmid-hempel P, Schmid-hempel R, Song J, Schwarz RS (2016) The bee microbiome: impact on bee health and model for evolution and ecology of host-microbe interactions. mBio 7(2):e02164-15. https://doi.org/10.1128/ mBio.02164-15

Dakal TC, Kumar A, Majumdar RS, Yadav V (2016) Mechanistic basis of antimicrobial actions of silver nanoparticles. Front Microbiol 7:1831. https:// doi.org/10.3389/fmicb.2016.01831

Ding J, Zhu D, Hong B, Wang HT, Li G, Ma YB, Tang YT, Chen QL (2019) Longterm application of organic fertilization causes the accumulation of antibiotic resistome in earthworm gut microbiota. Environ Int 124:145-152. https://doi. org/10.1016/J.ENVINT.2019.01.017

Engel P, Moran NA (2013) The gut microbiota of insects - diversity in structure and function. FEMS Microbiol Rev 37(5):699-735. https://doi.org/10.1111/1 574-6976.12025

Fabrega J, Luoma SN, Tyler CR, Galloway TS, Lead JR (2011) Silver nanoparticles: behaviour and effects in the aquatic environment. Environ Int 37(2):517-531. https://doi.org/10.1016/j.envint.2010.10.012

Flyg C, Kenne K, Boman HG (1980) Insect pathogenic properties of Serratia marcescens: phage-resistant mutants with a decreased resistance to Cecropia immunity and a decreased virulence to drosophila. Microbiology 120(1):173181. https://doi.org/10.1099/00221287-120-1-173

Funkhouser $L$, Bordenstein SR (2013) Mom knows best: the universality of maternal microbial transmission. PLoS Biol 11(8):e1001631. https://doi.org/1 0.1371/journal.pbio.1001631

Garland JL (1999) Potential and limitations of BIOLOG for microbial community analysis. In: Bell CR, Brylinsky M, Johnson-Green P (eds) Proceedings of the 8th International Symposium on Microbial Ecology Atlantic Canada Society for Microbial Ecology

Gottschalk F, Sun T, Nowack B (2013) Environmental concentrations of engineered nanomaterials: review of modeling and analytical studies. Environ Pollut 181:287-300. https://doi.org/10.1016/j.envpol.2013.06.003

Gupta AK, Dharne MS, Rangrez AY, Verma P, Ghate HV, Rohde M, Patole MS, Shouche YS (2011) Ignatzschineria indica sp. nov. and Ignatzschineria ureiclastica sp. nov., isolated from adult flesh flies (Diptera: Sarcophagidae). Int J Syst Evol Microbiol 61(6):1360-1369. https://doi.org/10.1099/ijs.0.01 $8622-0$

Hammer $\varnothing$, Harper DAT, Ryan PD (2001) PAST: paleontological statistics software package for education and data analysis. Palaeontologia Electronica.

Heijtz RD, Wang S, Anuar F, Qian Y, Bjorkholm B, Samuelsson A, Hibberd ML, Forssberg H, Pettersson S (2011) Normal gut microbiota modulates brain development and behavior. Proc Natl Acad Sci USA 108(7):3047-3052. https://doi.org/10.1073/pnas.1010529108 
Ho J, Tumkaya T, Aryal S, Choi H, Claridge-Chang A (2019) Moving beyond P values: data analysis with estimation graphics. Nat Methods 16(7):565-566. https://doi.org/10.1038/s41592-019-0470-3

Hsiao EY, McBride SW, Hsien S, Sharon G, Hyde ER, McCue T, Codelli JA, Chow J, Reisman SE, Petrosino JF, Patterson PH, Mazmanian SK (2013) Microbiota modulate behavioral and physiological abnormalities associated with neurodevelopmental disorders. Cell 155(7):1451-1463. https://doi.org/10.101 6/j.cell.2013.11.024

Hunting ER, Barmentlo SH, Schrama M, van Bodegom PM, Zhai Y, Vijver MG (2017) Agricultural constraints on microbial resource use and niche breadth in drainage ditches. PeerJ 5:e4175. https://doi.org/10.7717/peerj.4175

Hunting ER, de Goeij JM, Asselman M, van Soest RWM, van der Geest HG (2010) Degradation of mangrove-derived organic matter in mangrove associated sponges. Bull Mar Sci 86(4):871-877. https://doi.org/10.5343/bms.2010.1001

Hunting ER, Franken O, Knopperts F, Kraak MH, Vargas R, Röling WF, van der Geest HG (2013) Substrate as a driver of sponge distributions in mangrove ecosystems. Marine Ecol Progr Series 486:133-141. https://doi.org/10.3354/ meps 10376

Hunting ER, Vonk JA, Musters CJM, Kraak MH, Vijver MG (2016) Effects of agricultural practices on organic matter degradation in ditches. Sci Rep 6: 21474

Ip M, Lui SL, Poon VKM, Lung I, Burd A (2006) Antimicrobial activities of silver dressings: an in vitro comparison. J Med Microbiol 55(1):59-63. https://doi. org/10.1099/jmm.0.46124-0

Jacobs CGC, Wang Y, Vogel H, Vilcinskas A, van der Zee M, Rozen DE (2014) Egg survival is reduced by grave-soil microbes in the carrion beetle, Nicrophorus vespilloides. BMC Evol Biol 14(1):208. https://doi.org/10.1186/ s12862-014-0208-X

Jin Y, Wu S, Zeng Z, Fu Z (2017) Effects of environmental pollutants on gut microbiota. Environ Pollut 222:1-9. https://doi.org/10.1016/J.ENVPOL.201 6.11 .045

Judy JD, Unrine JM, Bertsch PM (2011) Evidence for biomagnification of gold nanoparticles within a terrestrial food chain. Environ Sci Technol 45(2):776781. https://doi.org/10.1021/es103031a

Kaltenpoth M, Steiger S (2014) Unearthing carrion beetles' microbiome: characterization of bacterial and fungal hindgut communities across the Silphidae. Mol Ecol 23(6):1251-1267. https://doi.org/10.1111/mec.12469

Kampfraath AA, Hunting ER, Mulder C, Breure AM, Gessner MO, Kraak MHS, Admiraal W (2012) DECOTAB: a multipurpose standard substrate to assess effects of litter quality on microbial decomposition and invertebrate consumption. Freshw Sci 31(4):1156-1162. https://doi.org/10.1899/12-075.1

Kau AL, Ahern PP, Griffin NW, Goodman AL, Gordon Jl (2011) Human nutrition, the gut microbiome and the immune system. Nature 474(7351):327-336. https://doi.org/10.1038/nature10213

Krause S, Le Roux X, Niklaus PA, Van Bodegom PM, Lennon JT, Bertilsson S, Grossart H-P, Philippot L, Bodelier PLE (2014) Trait-based approaches for understanding microbial biodiversity and ecosystem functioning. Front Microbiol 5:251. https://doi.org/10.3389/fmicb.2014.00251

Lehman RM, Lundgren JG, Petzke LM (2009) Bacterial communities associated with the digestive tract of the predatory ground beetle, Poecilus chalcites, and their modification by laboratory rearing and antibiotic treatment. Microb Ecol 57(2):349-358. https://doi.org/10.1007/s00248-008-9415-6

Mattey SN, Strutt L, Smiseth PT (2013) Intergenerational effects of inbreeding in Nicrophorus vespilloides: offspring suffer fitness costs when either they or their parents are inbred. J Evol Biol 26(4):843-853. https://doi.org/10.1111/ jeb.12102

Merrifield DL, Shaw BJ, Harper GM, Saoud IP, Davies SJ, Handy RD, Henry TB (2013) Ingestion of metal-nanoparticle contaminated food disrupts endogenous microbiota in zebrafish (Danio rerio). Environ Pollut 174:157-163. https://doi.org/10.1016/j.envpol.2012.11.017

Motta EVS, Raymann K, Moran NA (2018) Glyphosate perturbs the gut microbiota of honey bees. Proc Natl Acad Sci USA 115(41):10305-10310. https://doi. org/10.1073/pnas.1803880115

Oaks JL, Gilbert M, Virani MZ, Watson RT, Meteyer CU, Rideout BA, Shivaprasad HL, Ahmed S, Chaudhry MJ, Arshad M, Mahmood S, Ali A, Khan AA (2004) Diclofenac residues as the cause of vulture population decline in Pakistan. Nature 427(6975):630-633. https://doi.org/10.1038/nature02317

Pillai S, Behra R, Nestler H, Suter MJ-F, Sigg L, Schirmer K (2014) Linking toxicity and adaptive responses across the transcriptome, proteome, and phenotype of Chlamydomonas reinhardtii exposed to silver. Proc Natl Acad Sci USA 111(9):3490-3495. https://doi.org/10.1073/pnas.1319388111
Schrama M, Barmentlo SH, Hunting ER, van Logtestijn RS, Vijver MG, van Bodegom PM (2017) Pressure-induced shifts in trophic linkages in a simplified aquatic food web. Front Environ Sci 5:75. https://doi.org/10.3389/ fenvs.2017.00075

Shukla SP, Plata C, Reichelt M, Steiger S, Heckel DG, Kaltenpoth M, Vilcinskas A, Vogel H (2018) Microbiome-assisted carrion preservation aids larval development in a burying beetle. Proc Natl Acad Sci USA 115(44):1127411279. https://doi.org/10.1073/pnas.1812808115

Sison-Mangus MP, Mushegian AA, Ebert D (2014) Water fleas require microbiota for survival, growth and reproduction. ISME J 9(1):59-67. https://doi.org/10.1 038/ismej.2014.116

Smith JJ, MCFeters GA (1996) Effects of substrates and phosphate on INT (2-(4iodophenyl)-3-(4-nitrophenyl)-5-phenyl tetrazolium chloride) and CTC (5cyano-2,3-ditolyl tetrazolium chloride) reduction in Escherichia coli. J Appl Bacteriol 80(2):209-215. https://doi.org/10.1111/j.1365-2672.1996.tb03212.x

Steiger S, Gershman SN, Pettinger AM, Eggert AK, Sakaluk SK (2011) Sex differences in immunity and rapid upregulation of immune defence during parental care in the burying beetle, Nicrophorus orbicollis. Funct Ecol 25(6): 1368-1378. https://doi.org/10.1111/j.1365-2435.2011.01895.x

Theng BKG, Yuan G (2008) Nanoparticles in the soil environment. Elements 4(6): 395-399. https://doi.org/10.2113/gselements.4.6.395

Tlili A, Jabiol J, Behra R, Gil-Allué C, Gessner MO (2017) Chronic exposure effects of silver nanoparticles on stream microbial decomposer communities and ecosystem functions. Environ Sci Technol 51(4):2447-2455. https://doi.org/1 0.1021 /acs.est.6b05508

van den Brule S, Ambroise J, Lecloux H, Levard C, Soulas R, De Temmerman P-J, Palmai-Pallag M, Marbaix E, Lison D (2015) Dietary silver nanoparticles can disturb the gut microbiota in mice. Part Fibre Toxicol 13(1):38. https://doi. org/10.1186/s12989-016-0149-1

Van der Lee GH, Hunting ER, Vonk JA, Kraak MHS (2020) Decomposition and consumption tablets (DECOTABs). In: Bärlocher F, Gessner M, Graça M (eds) Methods to study litter decomposition. Springer, Cham. https://doi.org/10.1 007/978-3-030-30515-4 57

Villéger S, Mason NWH, Mouillot D (2008) New multidimensional functional diversity indices for a multifaced framework in functional ecology. Ecology 89(8):2290-2301. https://doi.org/10.1890/07-1206.1

Wang Y, Rozen DE (2017) Gut microbiota colonization and Nicrophorus vespilloides throughout development. Appl Environ Microbiol 83(9):1-13. https://doi.org/10.1128/AEM.03250-16

Wilding LA, Bassis CM, Walacavage K, Hashway S, Leroueil PR, Morishita M, Maynard AD, Philbert MA, Bergin IL (2016) Repeated dose (28-day) administration of silver nanoparticles of varied size and coating does not significantly alter the indigenous murine gut microbiome. Nanotoxicology 10(5):513-520. https://doi.org/10.3109/17435390.2015.1078854

Wilson EE, Wolkovich EM (2011) Scavenging: how carnivores and carrion structure communities. Trends Ecol Evol 26(3):129-135. https://doi.org/10.101 6/J.TREE.2010.12.011

Zhai Y, Brun NR, Bundschuh M, Schrama M, Hin E, Vijver MG (2018) Microbiallymediated indirect effects of silver nanoparticles on aquatic invertebrates. Aquat Sci 80(4):44. https://doi.org/10.1007/s00027-018-0594-z

Zhai Y, Hunting ER, Wouters M, Peijnenburg WJGM, Vijver MG (2016) Silver nanoparticles, ions, and shape governing soil microbial functional diversity: nano shapes micro. Front Microbiol 7:1-9. https://doi.org/10.3389/fmicb.2016. 01123

\section{Publisher's Note}

Springer Nature remains neutral with regard to jurisdictional claims in published maps and institutional affiliations. 